\section{Reaction between Retinal and Phospholipid Components of Outer Segments of Rods from Cattle Retina}

THE formation of a new conjugated substance by the reaction between retinal and phospholipid components of outer segments of rods from cattle retina has been reported ${ }^{\mathrm{T}}$. This article describes details of separation by thin layer chromatography of a conjugated substance and its spectral characteristics.

Outer segments of rods were separated from the other retinal tissues using a modified sucrose gradient method ${ }^{2}$. The lipids were extracted at room temperature with a chloroform-methanol mixture (2:1) from freshly prepared outer segments of rods that had been dehydrated by grinding with anhydrous sodium sulphate. The extract was washed twice with ion-free water to remove impurities $^{3}$. After the solvent had evaporated, the lipids were dissolved in the developing solvent (see later) to which was also added excess crystalline all-trans retinal. The original colour of the mixture was yellow but changed slowly to orange during the reaction, which was complete within about $1 \mathrm{~h}$ at $15^{\circ} \mathrm{C}$. The solution was then spread on thin layer chromatoplates of 'Silica Gel G' (Merck) 30 microns thick. When developed with acid solvent (chloroform-methanol-acetic acid $65: 25: 8$ by volume) it showed two coloured spots near the solvent front of the ascending chromatograph. The top spot was obviously caused by excess retinal, and the orange spot $\left(R_{F}\right.$ value of $0.88 \pm 0.05$ at $15^{\circ} \mathrm{C}$ ) by the product of the reaction. To complete the separation of these two spots, the plate was developed with a second non-polar solvent (petroleum ether-diethyl ether-acetic acid $80: 20: 1$ by volume), which allows only retinal to move to the solvent front. The orange spot area was isolated with a fine spatula and dissolved in acid solvent (chloroformmethanol-acetic acid- $\mathrm{H}_{2} \mathrm{O} 25: 15: 4: 2$ by volume) for spectral measurement. Fig. $l$ shows the absorbance of the conjugated substance. The reversible shift of absorbance between acid and alkaline conditions charac-

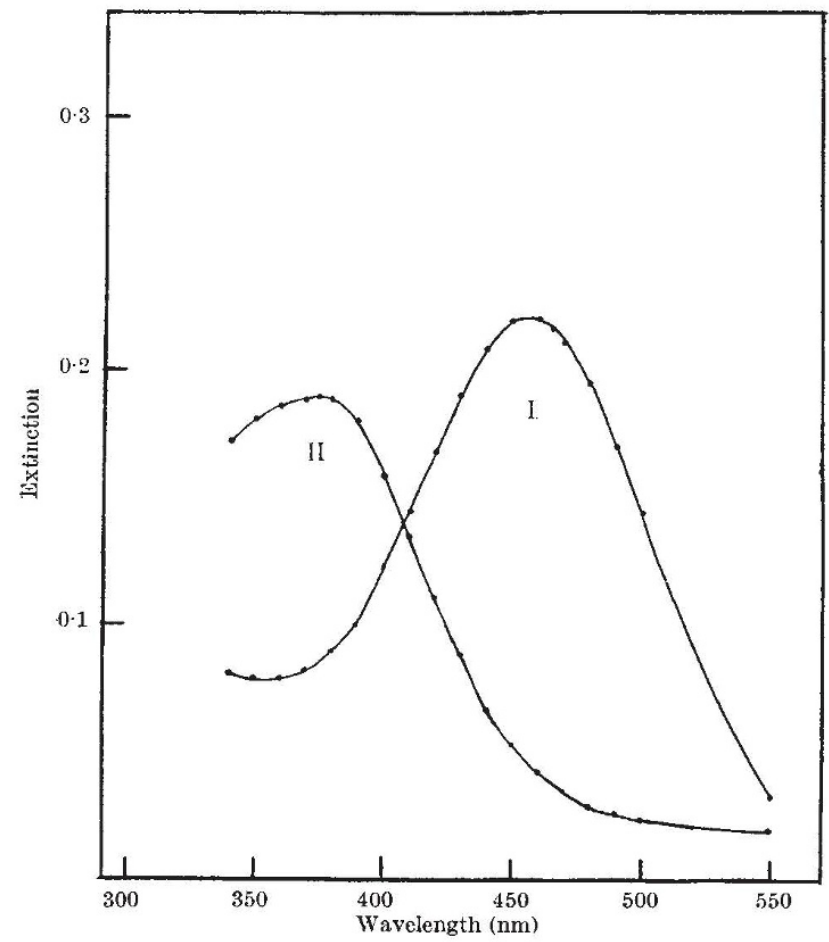

Fig. 1. Absorbance of retinal/phosphatidylethanolamine complex as a function of $p \mathrm{H}$. Spectrum I at $p \mathrm{H} 3 \cdot 4\left(\lambda_{\max } 460 \mathrm{~nm}\right)$ shifted to spectrum II $\left(\lambda_{\max } 375 \mathrm{~nm}\right.$ ) when the solution was brought to $p \mathrm{H} 9.0 \mathrm{by}$ the addi-
tion of a small amount of methanolic sodium bydroxide. $p \mathrm{H} 9 \cdot 0$ curve tion of a small amount of methanolic sodium by
was corrected for dilution. terizes this substance as an acid-base indicator. The two peaks are close to the peaks of acid and alkaline indicator yellow $^{4}$ respectively and their several analogues ${ }^{5}$. To identify which components of phospholipids react with retinal, wo sprayed all-trans retinal dissolved in acid solvent on phospholipids previously separated on the chromatoplate. Only one spot with intense ninhydrin reaction and $R_{F}$ value of $0.6 \pm 0.07$ appeared as an orange spot. As a result of a comparison of this reactive material with standard materials (Mann Research Laboratory and Pierce Biochemicals, USA) which were run parallel to the phospholipids of outer segments of rods on the chromatoplate, we believe that the conjugated substance exists as a Schiff's base linkage between phosphatidylethanolamine in the outer segments of rods and in the retinal. Phosphatidylethanolamine is one of the principal phospholipid components in outer segments of cattle rods and it represents approximately 25 per cent of total phospholipids of the tissue ${ }^{6}$. One cattle rhodopsin micelle ( $\left.E_{400 m m i c r o n s} / E_{500 m m i c r o n s}: 0.319\right)$ seems to contain more than five molecules of phosphatidylethanolamine $^{7}$. This suggests that phosphatidylethanolamine in the outer segments of rods plays some part in the bleaching process of rhodospin.

Biological Laboratory,

Isao Fukami

Nagoya Gakuin University,

Seto-shi, Aichi-ken, Japan.

Nutritional Laboratory,

Yoshiko Fuka

Tezukayama Junior College,

Nara-shi, Japan.

Received March 25, 1969.

${ }^{I}$ Fukami, I., and Fukami, Y., Fifth Ann. Meet. Biophys. Soc., Japan, Kyoto (1966).

2 Saito, Z., Tohoku J. Exp. Med., 42,432 (1938).

"Folch, J., Ascoli, I., Lees, M., Meath, J. A., and LeBaron, F. N., J. Liol. Chem., 191, 833 (1951)

' Collins, F. D., Nature, 171, 469 (1953).

${ }^{5}$ Ball, S., Collins, F. D., Dalvi, P. D., and Morton, R. A., Biochem. J., 45, $30+$ (1949).

${ }^{6}$ Fukami, I., Nagoya Gakuin Rev., 12, 232 (196i).

${ }^{7}$ Fukami, I., Maeda, Y., and Fukami, Y., Fifth Intern. Cong. Photobiclogy, Hanover (1968)

\section{Molecular Nature of the Heat of Shortening of Muscle}

Shortening of muscle during single isotonic twitehes and following a tetanic stimulus is accompanied by the development of extra heat ${ }^{1-3}$. The heat of shortening veries with the distance shortened and depends also on the load lifted by the muscle 4 . Although it is generally agreed that the heat developed during work done by the muscle can be accounted for by the energy of ATP splitting $^{5,6}$, there appears to be no evidence of changes in the high-energy phosphate level accompanying the actual shortening 7,8 .

To study the molecular mechanism responsible for the occurrence of heat of shortening, glycerinated muscle fibres have now been used; they were allowed to shorten isotonically in the presence of a non-hydrolysable ATP analogue in conditions such that the muscle could not do external work.

The experimental material was $u$ hole dorsal longitudinal muscle of the tropical water bug Lethocerus maximus, which was glycerinated in situ by the procedure of Abbott and Chaplain'. These muscles contain between 6,450 and 7,300 fibres (average, 6,830). After glycerination the weight of a $1 \mathrm{~cm}$ long piece of an average drained muscle is $137 \mathrm{mg}$. The muscle was cemented on flat anodized aluminium disks with 'Duco' cement, one end being attached to an RCA 5734 tension transducer, the other to 